${ }^{2}$ Stichting Epilepsie Instellingen Nederland, Heemstede/Zwolle

\title{
3D-multimodale beeldintegratie bij invasieve diagnostiek en behandeling van focale epilepsie
}

In deze bijdrage worden twee casussen gepresenteerd, waarbij 3 D-multimodale modellen zijn gemaakt voor focuslokalisatie. Op basis van preoperatieve beeldvorming met onder andere PET en MEG werden subdurale elektrodengrids geplaatst. Uit het resultaat blijkt dat $3 \mathrm{D}$-multimodale beeldintegratie bijdraagt aan een meer gerichte implantatiestrategie van de subdurale grids en in samenhang daarmee aan een grotere kans op een succesvolle operatie.

Patiënten met refractaire focale epilepsie die een invasieve EEG-registratie moeten ondergaan voor nadere focusbepaling, krijgen eerst vaak een scala aan niet-invasieve onderzoeken. Om inzicht te krijgen in de resultaten van de opeenvolgende onderzoeken is het zinvol deze te integreren in een $3 \mathrm{D}$-multimodaal hersenmodel van de patiënt. Het hersenmodel is een reconstructie van het hersenvolume met daarin grijze en witte stof, op basis van een hoge resolutie (3 Tesla) MRI-scan. Alle informatie die iets zegt over de mogelijke bron van de epilepsie kan hierin worden ingetekend met voor ieder onderzoek een eigen kleur. Dit gebeurt door de afwijking in elk onderzoek te segmenteren of te omgrenzen, wat meestal met de hand gebeurt, en vervolgens het onderzoek te co-registreren met het MRI-hersenmodel. Dit kan een anatomische afwijking betreffen (vastgesteld met MRI, meestal in een FLAIR-sequentie), maar vaak gaat het om informatie uit functie-onderzoek (bronlokalisatie met EEG of MEG, hypometabolisme op FDG-PET of hyperperfusie op een ictale SPECT of simultaan EEG en AMRI). In het Universitair Medisch Centrum (UMC) in Utrecht wordt het programma EpiNav gebruikt, dat is ontwikkeld door University College London (Nowell et al., 2015).

Het multimodale model toont de locaties van de gevonden afwijkingen ten opzichte van elkaar en is daarom een handige hulp bij het bepalen waar het invasieve EEG zich op moet richten. Het kan tevens gebruikt worden voor het opstellen van een chirurgisch plan door ook informatie over fysiologische functies te integreren zoals taal en motoriek (bijvoorbeeld op basis van fMRI). In deze bijdrage worden twee casussen besproken, waarbij $3 \mathrm{D}$-multimodale beeldintegratie de invasieve diagnostiek heeft geholpen. In beide gevallen gaat het hier om subdurale grid-implantaties, maar dezelfde principes gelden voor stereo-EEG met diepte-elektroden.

\section{Casus I}

De eerste casus betreft een vijftienjarige jongen met aanvallen sinds de leeftijd van elf jaar, ontstaan één maand na licht schedel-hersenletsel. Tijdens de eerste aanval had hij schokjes in de rechterarm en enkele maanden later een eerste gegeneraliseerd tonisch-clonisch insult. De huidige (preoperatieve) aanvallen beginnen met een zwaar gevoel in het hoofd dat naar zijn voeten trekt. Hij heeft pijn in zijn rechterarm en voelt voordat het zover is dat hij een aanval krijgt. De rechterarm verstijft en het rechterbeen strekt, het gelaat rechts zakt naar beneden. Vervolgens krijgt hij schokken over het hele lichaam. Hij weet daarna niets meer en is duizelig als hij bijkomt. Er is krachtsvermindering in de rechterarm na een aanval. Deze aanvallen treden meerdere malen per avond of nacht op. Hij gebruikt clobazam, levetiracetam en zo nodig midazolam neusspray. De MRI ( $3 \mathrm{~T}$ en $7 \mathrm{~T}$ ) vertoont geen afwijkingen. Bij een EEGaanvalsregistratie wordt een discrete asymmetrie ten nadele van links centropariëtaal, met interictaal reeksen piekgolven midpariëtaal, uitbreidend naar links parasagittaal en de vertex waargenomen. Bij acht geregistreerde aanvallen is er een aanvalsbegin midpariëtaal te zien, later lateraliserend naar links. Vervolgens wordt op een FDG-PET een interictaal hypometabolisme links hoogpariëtaal waargenomen. MEG laat scherpe golven zien die met bronlokalisatie links centropariëtaal worden gelokaliseerd. Bij genetisch onderzoek wordt een mutatie in het $\mathrm{DEPDC}_{5}$ gen gevonden, die gecorreleerd is met het hebben van focale corticale dysplasie. Post-processing van de MRI met MAPo7 (Widman et al., 20I8) laat nog steeds geen verdachte plekken links frontaal of pariëtaal zien.

Op basis van deze informatie werd een $3 \mathrm{D}$-multimodaal model gemaakt met de resultaten van PET en MEG (figuur IB). In dit model is duidelijk te zien dat het PET hypome- 
tabolisme en de MEG-bron convergeren in hetzelfde gebied zonder te overlappen. Om de epileptische bron verder af te bakenen ten opzichte van de motorische en sensorische functiegebieden, worden subdurale gridelektroden links frontaal, centraal en pariëtaal parasagittaal geïmplanteerd (figuur IC). In verband met ankervenen lukt het niet om het MEG-gebied volledig te bedekken. Het subdurale EEG wordt gedurende vier dagen gemeten met als resultaat dat er elf spontane klinische aanvallen worden geregistreerd, De aanvalsactiviteit begint met gamma-activiteit op één elektrode (rood in figuur $\mathrm{IC}$ ) en snel spreidend naar een naastgelegen elektrode (oranje in figuur $\mathrm{IC}$ ). Met elektrocorticale stimulatie wordt de somatosensibele representatie in kaart gebracht, waaruit blijkt dat het focus midden in het gebied van de sensibele been- en voetrepresentatie ligt, op de gyrus postcentralis. Er wordt besloten tot een kleine resectie van het gebied onder de twee elektroden waarmee het aanvalsbegin werd gemeten. De resectie wordt zo beperkt mogelijk gehouden vanwege de kans op neurologische uitval. Na de resectie heeft de patiënt een aanzienlijke aanvalsvermindering, zowel in frequentie als in intensiteit van de aanvallen, maar is na II maanden follow-up helaas niet aanvalsvrij. Een oppervlakte-EEG dat enkele weken na de operatie wordt gemaakt laat geen interictale afwijkingen meer zien.

\section{Casus 2}

De tweede casus is een zestienjarige jongen met aanvallen sinds zijn twaalfde. Hij voelt zijn aanvallen aankomen doordat hij duizelig wordt. Hij krijgt schokken in zijn armen en benen, waarbij hij bij bewustzijn blijft; daarna draaien zijn ogen naar links en kan hij niet goed meer zien. Daarnaast heeft hij tonisch-clonische insulten. Hij gebruikt levetiracetam. Het EEG toont een asymmetrisch grondpatroon ten nadele van rechts, met lange reeksen piekgolven rechts laag achtertemporaal. Tijdens een aanval is er betrokkenheid van een groot gebied rechts achtertemporaal en occipitaal. Op de MRI is er een dubieus verminderde grijs-witte stof afgrenzing rechts temporobasaal/ achtertemporaal zichtbaar, met een asymmetrisch gyratiepatroon, waarschijnlijk als gevolg van een aanlegstoornis. Ook op een $7 \mathrm{~T}$ MRI is er rechts temporobasaal een klein gebiedje in de witte stof met $\mathrm{T} 2$ hyperintensiteit zichtbaar, terwijl een FDG-PET afwijkend is in een gebied rechts temporo-occipitaal. De MEG-pieken zijn gelokaliseerd in rechts temporobasaal gebied en in de posterieure insula. Met deze gegevens wordt een $3 \mathrm{D}$-multimodaal model gemaakt (figuur 2), op basis waarvan besloten wordt tot een uitgebreide implantatie met een elektrodengrid temporaal, occipitaal en additioneel, drie elektrodenstrips basotemporaal (figuur $2 \mathrm{C}$ ). Hiermee worden de meeste gebieden bedekt; er wordt een keuze gemaakt om de posterieure insula niet te samplen.

Tijdens de invasieve registratie worden interictaal diffuus multifocale afwijkingen gemeten, met een continu piekpatroon op de donkerblauwe elektroden in figuur $2 \mathrm{C}$. Eén subklinische aanval laat een begin zien op de basotemporale strips (rood in figuur $2 \mathrm{C}$ ), met snelle spreiding diffuus over het temporale grid (met name naar de oranje elektroden van figuur $2 \mathrm{C}$ ). De rode grid-elektroden laten een opvallend interictaal continu piekpatroon zien. Daarnaast wordt een aanval opgewekt na elektrocorticale stimulatie, wederom op de voorste basotemporale elektrodenstrip. De bevindingen lijken het meest passend bij een diffuse temporale neocorticale aandoening. Er wordt daarom besloten tot een uitgebreide temporale resectie

\section{CASUS 1}

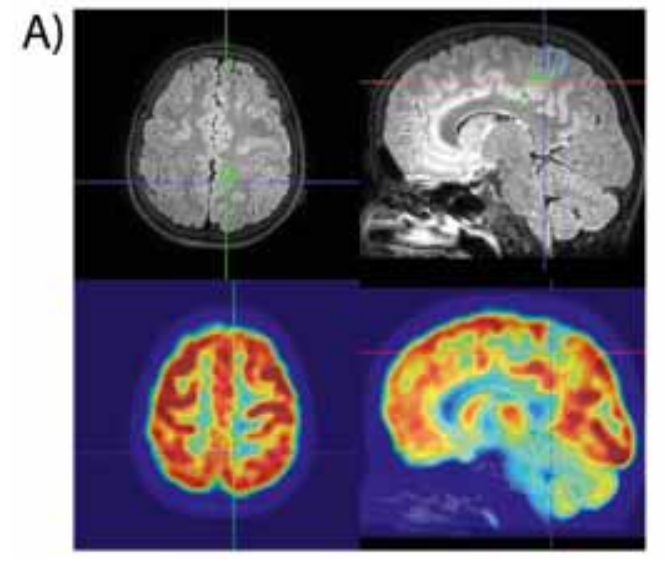

B)

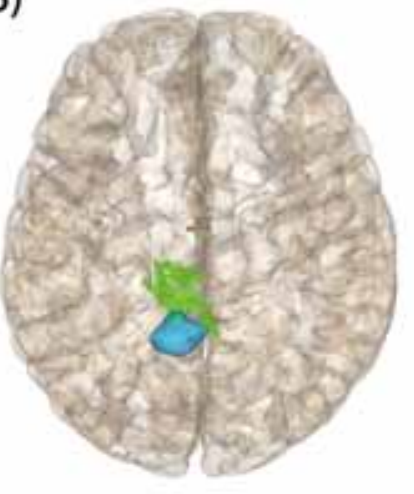

C)

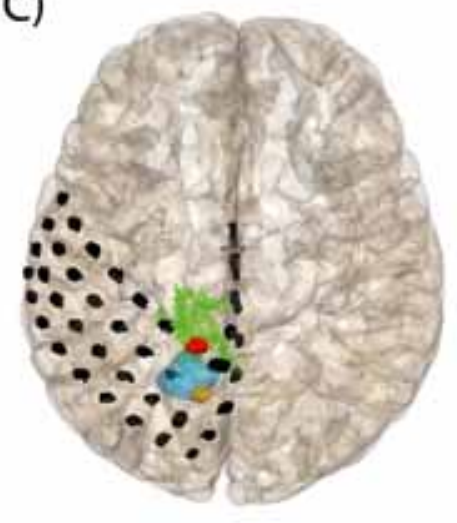

Figuur 1. Multimodaal model van casus 1. A) Afwijkend FDG-PET hypometabolisme (onder), blauw gekleurd gebied in een axiale en sagittale MRI-scan (boven) met tevens projectie van de MEG bronlokalisatie van interictale pieken (groen). B) Geprojecteerd op corticale rendering. C) Er werd een elektrodegrid centraal en een grid interhemisferisch geplaatst. De aanvallen toonden een aanvalsbegin op de rode grid-elektrode en spreidden daarna snel naar de oranje grid-elektrode. Het gebied onder deze twee elektroden werd geresecteerd. 


\section{CASUS 2}

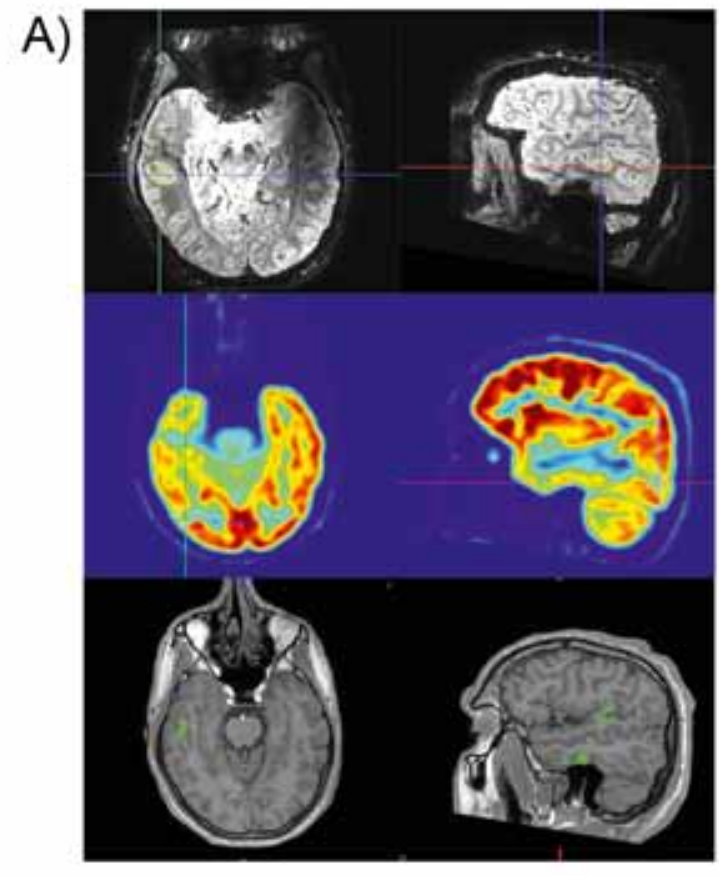

B)

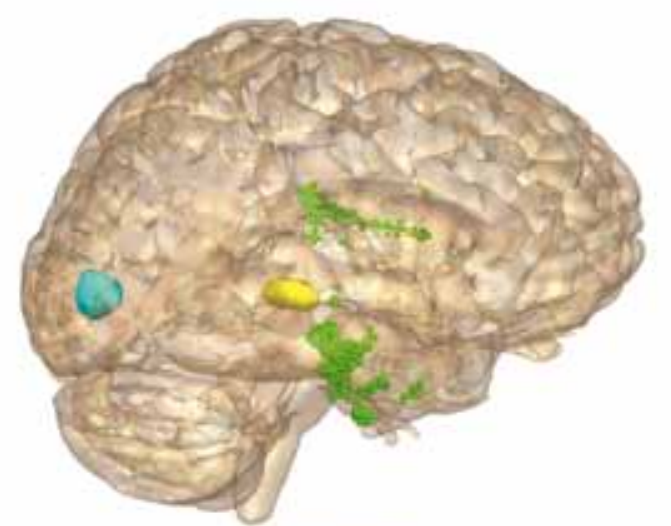

C)

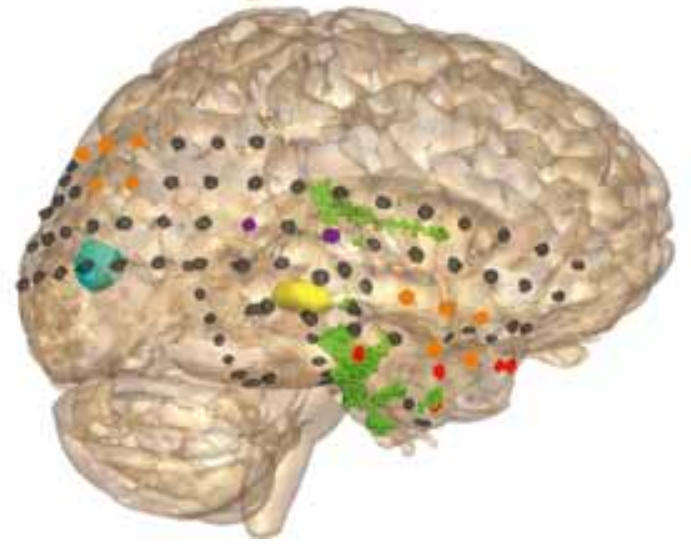

Figuur 2. Multimodaal model van casus 2. A) Er is een dubieuze laesie op de 7 T MRI (geel gearceerd in een axiale en sagittale MRI-scan (boven)), een FDG-PET hypometabolisme (links midden), en gelokaliseerde MEG-pieken (groen gekleurd in een axiale en sagittale MRI scan). B) Geprojecteerd op een sagittale corticale rendering is: de MRI lesie (geel), het FDG-PET hypometabolisme (blauw) en de gelokaliseerde MEG-pieken (groen). C) Het elektrodengrid werd geplaatst over het rechts temporale en temporo-occipitale gebied en de elektrodenstrips in het mesiotemporale gebied. Het begin van de aanvallen werd gemeten met de donkerrode gridelektroden en spreidde daarna snel naar de oranje gridelektroden. Op de donkerblauwe elektroden was een continu piekpatroon aanwezig. Er werd besloten tot een uitgebreide temporale resectie.

met als achtergrens de gebieden op de gyrus temporalis superior en subtemporaal waar een herkenbaar aura wordt opgewekt.

De pathologische analyse toont een milde corticale dysplasie (MCD). Een jaar na de operatie is de patiënt nog altijd aanvalsvrij.

\section{Conclusie}

De hier besproken cases laten zien dat het helpt om de resultaten van pre-chirurgische registraties samen te voegen in een multimodaal model, om tot een gerichte implantatiestrategie te komen. Intra-operatief worden de $3 \mathrm{D}$-modellen gebruikt om te checken dat de beoogde gebieden daadwerkelijk bedekt worden. De jongen van casus I is hier helaas niet aanvalsvrij mee geworden, omdat de resectie in het essentiële functiegebied waarschijnlijk niet volledig was. De jongen van casus 2 is wel aanvalsvrij, na een grote temporale resectie. Het multimodaal model laat al zien dat de verschillende onderzoeken, hoewel allemaal naar rechts temporaal wijzend, een groot gebied beslaan. Dit is de basis geweest voor de uitgebreide implantatie en resectie.
Driedimensionale multimodale beeldintegratie is niet voor elke patiënt een must, maar met de verschuiving in het type verwijzingen naar meer complexe casussen is het voor steeds meer patiënten een goede toevoeging.

\section{Referenties}

Nowell M, Rodionov R, Zombori G, Sparks R et al. (2015) Utility of ${ }_{3} \mathrm{D}$ multimodality imaging in the implantation of intracranial electrodes in epilepsy. Epilepsia. 2015 Mar:56(3):403-13.

Widman G, Huppertz HJ (20I8) Van een MRI-negatieve medicatieresistente epilepsie naar een goede operatiekandidaat. Epilepsie, Periodiek voor professionals 2018 16(1) 3-6 